\title{
Photoluminescence Response in Carbon Films Deposited by Pulsed Laser Deposition onto GaAs Substrates at Low Vacuum
}

\author{
F. Caballero-Briones, ${ }^{1}$ G. Santana, ${ }^{2}$ T. Flores, ${ }^{3}$ and L. Ponce ${ }^{3}$ \\ ${ }^{1}$ Instituto Politécnico Nacional, Materials and Technologies for Energy, Health and Environment Group (GESMAT), \\ CICATA Altamira, Km 14.5, Carretera Tampico-Puerto Industrial, 89600 Altamira, TAMPS, Mexico \\ ${ }^{2}$ Instituto de Investigaciones en Materiales, Universidad Nacional Autónoma de México, Ciudad Universitaria, \\ 04510 México City, Mexico \\ ${ }^{3}$ Instituto Politécnico Nacional, Laboratorio de Tecnología Láser, CICATA Altamira, Km 14.5 Carretera Tampico-Puerto Industrial, \\ 89600 Altamira, TAMPS, Mexico
}

Correspondence should be addressed to L. Ponce; lponce@ipn.mx

Received 2 September 2016; Revised 18 October 2016; Accepted 25 October 2016

Academic Editor: Marco Rossi

Copyright (C) 2016 F. Caballero-Briones et al. This is an open access article distributed under the Creative Commons Attribution License, which permits unrestricted use, distribution, and reproduction in any medium, provided the original work is properly cited.

Carbon films were deposited onto GaAs substrates by pulsed laser deposition at low vacuum (10-15 mTorr) from a graphite target. Films were prepared at different number of pulses (1500 to 6000) with fixed fluence $\left(32 \mathrm{~J} / \mathrm{cm}^{2}\right)$, target-to-substrate distance, and pulse frequency using a Q:Switched Nd:YAG laser at $1064 \mathrm{~nm}$ operating at a frequency of $10 \mathrm{~Hz}$ and producing burst-mode pulses with total duration per shot of $49 \mathrm{~ns}$. Films were characterized by optical microscopy, atomic force microscopy, laser induced breakdown spectroscopy, X-ray diffraction, and photoluminescence spectroscopy. Deposited films were visually smooth and adherent but on the other hand evidence of splashing was observed in all the films. Thickness varied linearly with the number of pulses from 8 to $42 \mu \mathrm{m}$ with maximum height differences around $700 \mathrm{~nm}$. Hexagonal and orthorhombic carbon was found in all the films and there was no evidence of nitrogen or oxygen incorporation during ablation process. Broad photoluminescence bands were observed and, particularly, emission peaks at $475-480 \mathrm{~nm}, 540-550 \mathrm{~nm}, 590 \mathrm{~nm}$, and $625 \mathrm{~nm}$. Bands tend to shift to lower wavelength with film thickness, suggesting that luminescence comes from splashed nanostructures influenced by the semiconducting substrate. This particular substrate effect is vanished as thickness of the films increases.

\section{Introduction}

Carbon nanomaterials have raised large interest for the possible applications in electronic devices, sensors, therapeutics, and so on. Particularly, carbon quantum dots (C-QDs) have been devised as the following generation of light emitting devices and tumor markers, between other applications [13]. Blue, green, and red emission from C-QDs have been reported in dependence of synthesis conditions such as the amount of oxygen and nitrogen or particle size, which modulate the extent of $\mathrm{sp}^{2}$ dominion within $\mathrm{sp}^{3}$ matrix [4]. Many synthesis techniques have been reported so far for C-QDs ([3] and references therein). Between them, pulsed laser deposition (PLD) has been reported for carbon QD preparation in aqueous media [4]. However, the prepared CQDs remain in solution and it is difficult to prepare solidstate devices for electronic applications. On the other side, splashing, or uncontrolled particle ejection, is a very common feature observed in PLD $[5,6]$. The removal of material particles during ablation depends mainly on laser fluence onto target surface, on laser wavelength, and on the material's spectral absorption; particles ranging some 50 microns down to few nanometers have been observed, depending on the predominant mechanisms underlying particle ejection, that correspondingly depend on the experimental conditions and the particular material [6]. Herein, we report the preparation of carbon films onto GaAs substrates and characterize the light emission from the carbon nanoparticles deposited 
by splashing and the effect of increasing thickness of the carbon film. Low vacuum PLD (LV-PLD) has been used because of the possibility of incorporating traces of $\mathrm{O}$ and $\mathrm{N}$ [7] that are reported to enhance C-QDs luminescence [4] while keeping film deposition low and therein controllable [8]. Our final goal is to propose LV-PLD as a faster and reliable method to prepare C-QD-based devices as well as hierarchical structures.

\section{Experimental Details}

Films were deposited onto nonintentionally heated GaAs substrates precleaned with isopropyl alcohol. The deposition was done using a burst-mode Nd:YAG laser operating at $1064 \mathrm{~nm}$ with a Cr:YAG passive Q-switch. This device emits laser shots in burst-mode regime, which produces shots composed by 7 pulses, each of them of 7 ns pulse width and time delay between pulses in range $20-25 \mu \mathrm{s}$. This Q-switch device is more compact and simpler to operate than the commonly used electrooptical switches, and its application to PLD has been previously reported for deposition of $\mathrm{BaFe}_{12} \mathrm{O}_{19}$ [9] and $\mathrm{SrFe}_{12} \mathrm{O}_{19}$ sintered ceramics $[10,11]$. The repetition rate of laser shots was $10 \mathrm{~Hz}$ and the laser was focused through a $200 \mathrm{~mm}$ lens to get a spot diameter onto the target of about $1 \mathrm{~mm}$. The target-to-substrate distance was kept at $50 \mathrm{~mm}$ and the fluence over the target was controlled at $32 \mathrm{~J} / \mathrm{cm}^{2}$. The vacuum system was an Alcatel $180 \mathrm{l} / \mathrm{min}$ mechanical pump. The pressure was monitored with a Pirani gauge and controlled through a flap valve at $10-15$ mTorr during film deposition. The target was a $25 \mathrm{~mm}$ diameter $\times 3 \mathrm{~mm}$ thick graphite rod ( $98 \%$ purity) mounted onto an eccentrically rotating device. Films were prepared at 1500, 3000, 4500, and 6000 laser shots corresponding to deposition times of $2.5,5,7.5$, and $10 \mathrm{~min}$, respectively. Films were characterized by optical microscopy in AM Scope MT130 microscope; by atomic force microscopy (AFM) in the contact mode with Si tips using a TT AFM Workshop microscope; by laser induced breakdown spectroscopy (LIBS) using a Nd:YAG laser and an Ocean Optics spectrometer that analyzes the light coming the plasma collected with an optic fiber; and by $\mathrm{X}$-ray diffraction (XRD) in the grazing incidence geometry using $\mathrm{CuK} \alpha$ radiation in a D8 Advance Bruker diffractometer. Photoluminescence response (PL) was measured by exciting the sample with a $325 \mathrm{~nm} \mathrm{He}-\mathrm{Cd}$ laser and collecting the sample emission with an spectrometer in the visible range. Emission from laser was blocked using notch filters.

\section{Results and Discussion}

Figure 1 presents the $40 \mathrm{x}$ optical micrographs of the prepared film surfaces. The micrographs show the splashing effect on the samples surface as reported in previous studies [10, 11]. In this work, the splashed microparticles are observed in all the films. However, the increase of irradiation time, which leads to growth in the film thickness, causes smaller particles to remain embedded in the layer and a less quantity of microparticles is observed on the film surface. In Figure 1(c) fewer particles are observed, and these are bigger in size, possibly because of particle coalescence upon surface heating.
Figure 2 shows the micrograph of a film lateral cut from the freshly cleaved wafer, corresponding to the film prepared with $5 \mathrm{~min}$ irradiation time. By this method the films thickness was measured for the different irradiation times.

The thickness dependence on the number of pulses is plotted in Figure 3. The average deposition rate was $6.93 \mathrm{~nm} /$ pulse, in the same order of magnitude of a silver target ablated in a 0.04 mbar Ar atmosphere [8].

It should be noted that this dependence is based on the average thickness of the films, since the roughness of the samples, as measured by AFM, ranges from 0.65 to $0.71 \mu \mathrm{m}$. The irregularities in the surface relief are due to several causes, including the splashing effect, but also the formation of surface structures during the films growth process [6].

By LIBS analysis, only carbon and gallium from the GaAs substrate were noticed. Correspondingly, Figure 4 presents the XRD diffractograms from the film prepared with $10 \mathrm{~min}$ of irradiation. A strong peak at $24.6^{\circ}$ corresponding to the orthorhombic phase of graphite (PDF-742330) and a peak at $26.4^{\circ}$ related with the (002) reflection of hexagonal graphite (PDF-411487) coming from the target can be observed. Another strong reflection is observed at $26.2^{\circ}$. This reflection cannot be assigned to any other phase than hexagonal graphite with an increased interplanar distance. This is possible due to some oxygen groups that could be intercalated between adjacent graphite layers during ablation; thus, the presence of expanded graphite can be considered in the present case [12]. A more extensive study that will include Raman and infrared spectroscopy is in process to unveil the microstructure of the deposited films. The presence of orthorhombic graphite is attributed to splashed particles. Finally, peaks at $22.6^{\circ}, 25.2^{\circ}$, and $26.9^{\circ}$ are observed. These peaks could be associated with polyaromatic clusters around 20-22 carbon atoms, such as anthanthrene $\left(\mathrm{C}_{22} \mathrm{H}_{12}\right)$ (PDF040089 , main reflection at $22.45^{\circ}$ ) which have diffraction peaks close to the observed ones, consistently with the observations of Murray and Peeler for ejected carbon [5]. A detailed study varying the fluence could lead to a changeable and controllable distribution of these polyaromatic clusters.

Figure 5 presents the images of the surface morphology obtained by AFM in the films prepared with 2.5 and $10 \mathrm{~min}$ of growth (Figures 5(a), 5(c), 5(b), and 5(d), resp.) as well as line profiles to estimate the grain sizes (Figures 5(e) and 5(f)).

The variation of the surface morphology that can be seen in the images allows observing some aspects of interest. The AFM image of the layer obtained at $2.5 \mathrm{~min}$ irradiation (Figure 5(a)) shows noticeable particles, which due to their shape and volume can be attributed to the splashing effect [5, 6]. The analysis of the profiles shown in Figure 5(e) indicates that the entities are of two different kinds. There are large particles around $300 \mathrm{~nm}$ high that could be indeed splashing and regular ones about $60 \mathrm{~nm}$ more related to the smaller clusters detected by X-ray diffraction. Figure 5(b) displays the 3D image of the film prepared with $10 \mathrm{~min}$ of irradiation. The typical substrate characteristics are no longer observed. Film surface is rough and consists of longitudinal structures with entities of varied sizes spread all over it. Figure 5(d) displays clearly the type of spread entities; there are large ones that 


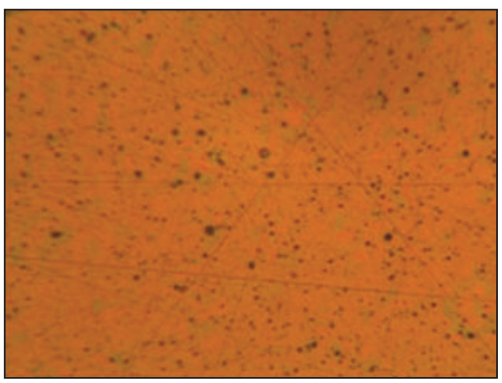

(a)

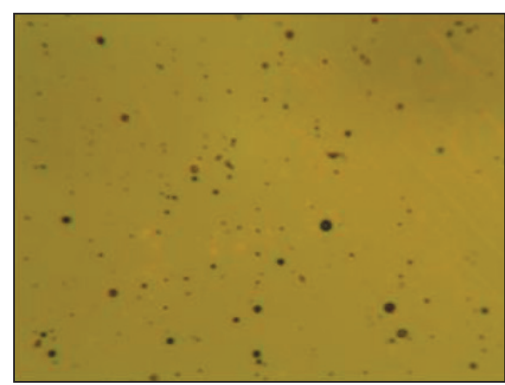

(b)

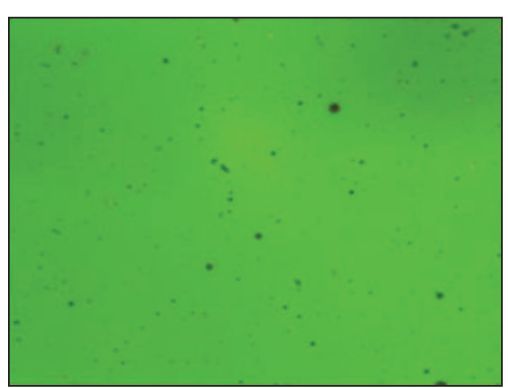

(c)

FIgURE 1: Optical micrographs (40x) of the films prepared with irradiation times of (a) $2.5 \mathrm{~min}$ (b) $7.5 \mathrm{~min}$, and (c) $10 \mathrm{~min}$.

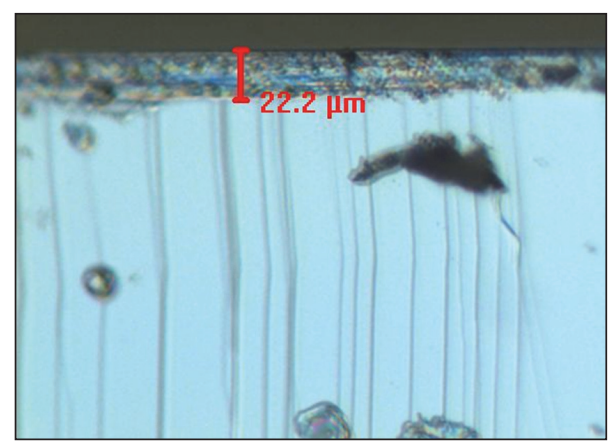

FIGURE 2: Optical micrograph of the lateral cut of the film prepared with an irradiation time of $5 \mathrm{~min}$ (40x magnification).

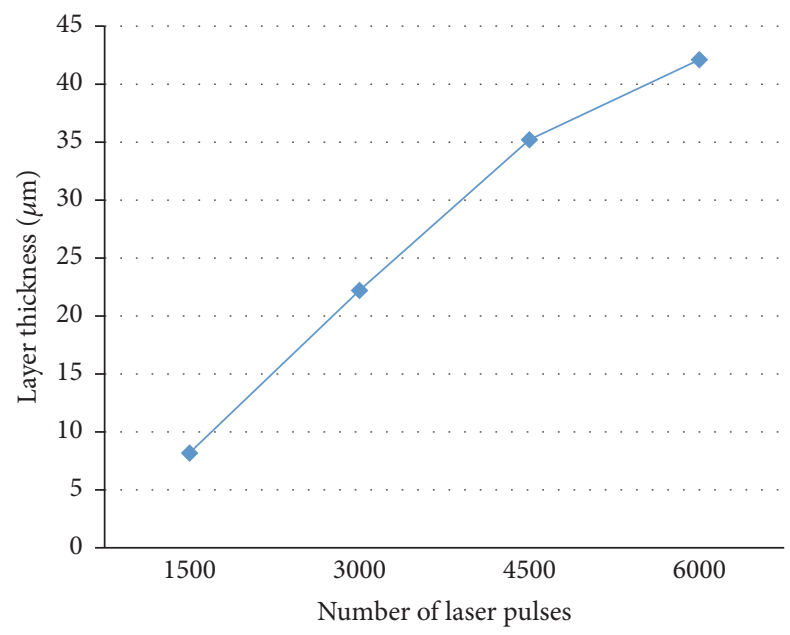

FIGURE 3: Film thickness versus number of pulses.

clearly correspond to splashing and there are smaller particles around $50 \mathrm{~nm}$ high (Figure 5(f)) that would correspond to the carbon clusters or, indeed, carbon nanodots, arising from the ablated carbon clusters [5]. Figures S1 and S2 (Supplementary Information) in Supplementary Material, available online at http://dx.doi.org/10.1155/2016/5349697, display detail of the AFM images as well as the height distributions measured in selected regions of the AFM images. The histograms indicate that grain heights are in the order of $50 \mathrm{~nm}$ for the film

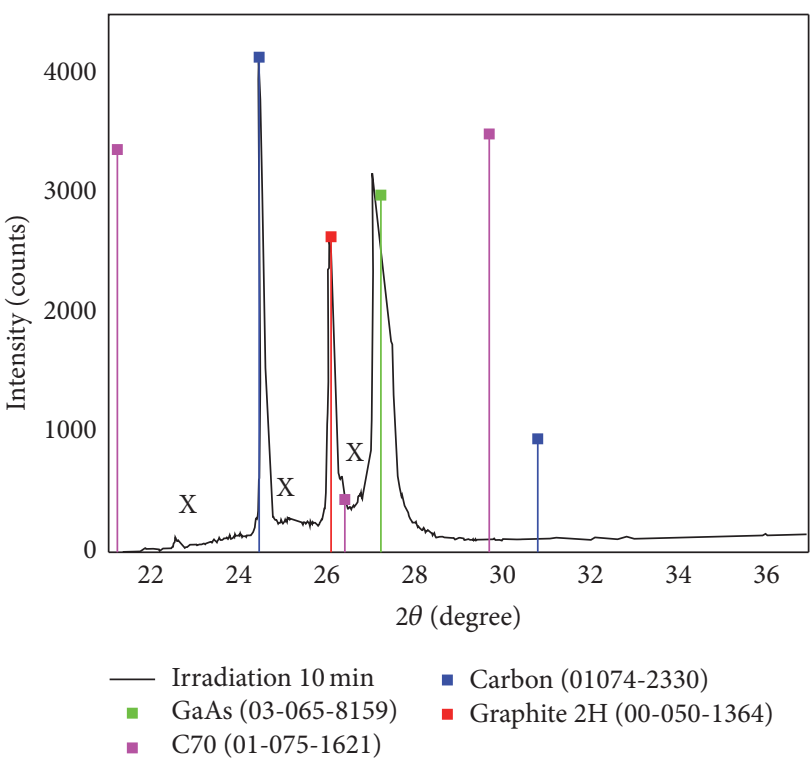

FIGURE 4: X-ray diffractogram of the film obtained with a $10 \mathrm{~min}$ irradiation.

obtained at $2.5 \mathrm{~min}$ of irradiation and distributed between 30 and $120 \mathrm{~nm}$ for the film prepared at $10 \mathrm{~min}$ of irradiation, respectively.

Figure 6 presents the photoluminescence response of the films. The spectrum of the film prepared at 1500 shots was multiplied 10 times for visualization. Figure 6(b) presents the already discussed film thickness estimated from the optical microscope lateral profiles. The very low PL response for the 1500 shot sample can be attributed to absorption effect of the GaAs substrate [1]. Figure 6(c) presents the deconvolution of the spectrum in 4 emission lines at $482,525,577$, and $634 \mathrm{~nm}$, respectively. The same bands were identified for all the films. These bands have been reported for C-QDs [3] as well as for reduced graphene oxide [2, 4]. Blue shift emission of the 470-480 and 500-525 bands is observed for all the films (Figure 6(d)). An increase of the relative intensity of the same bands is observed as the film thickness increases.

Cuong et al. [2] mentioned that PL in amorphous carbon arises from radiative recombination in band-tail states created by $\mathrm{sp}^{2}$ clusters; indeed, in our samples crystalline carbon 


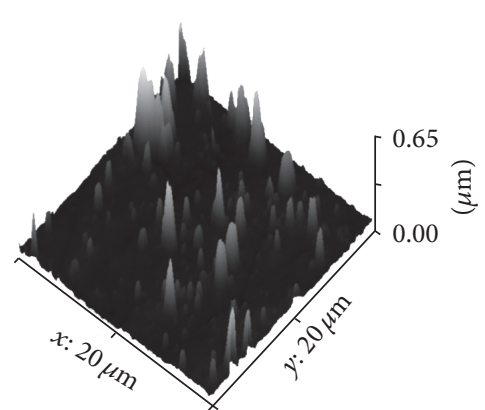

(a)

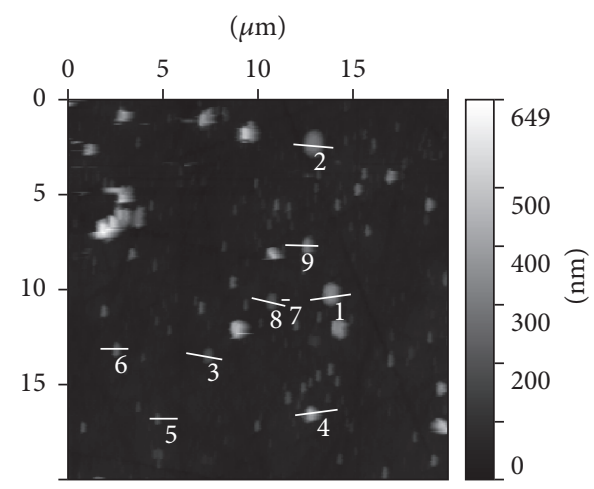

(c)
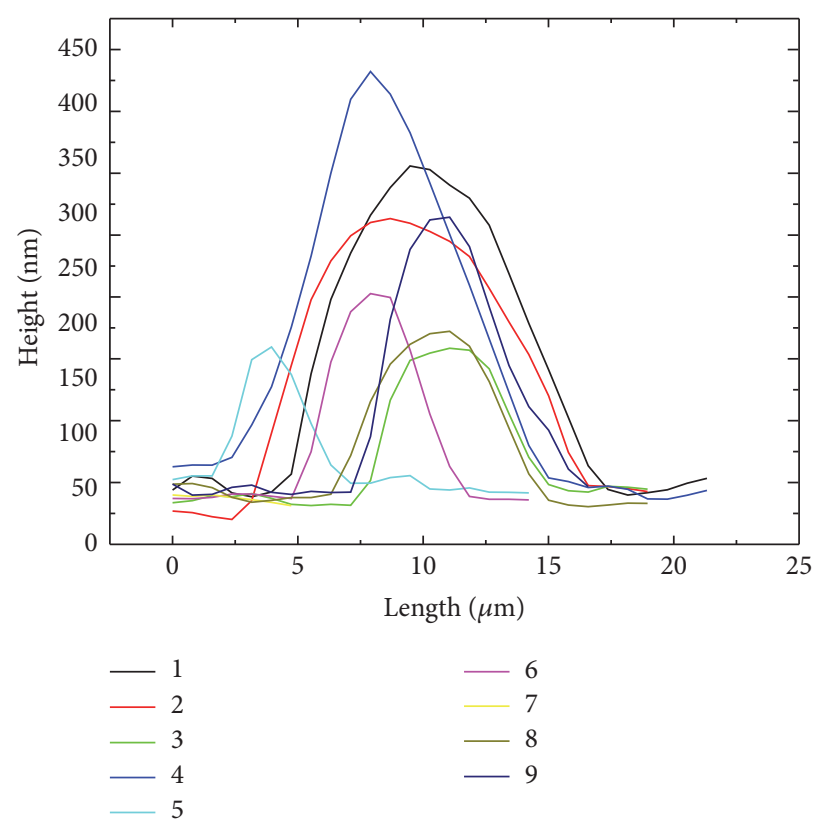

(e)

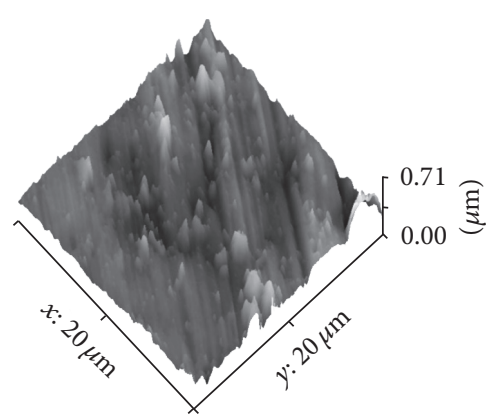

(b)

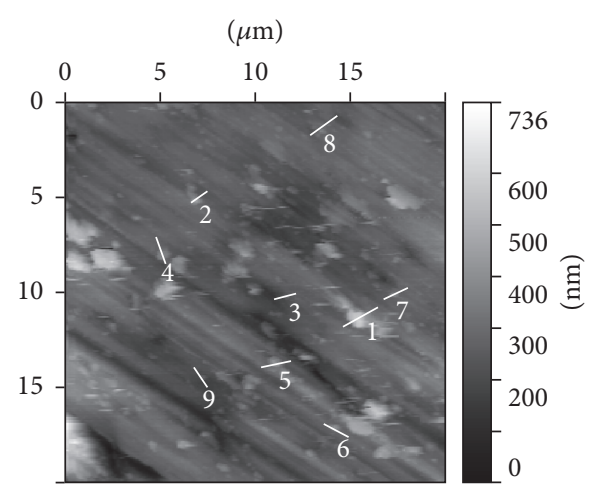

(d)
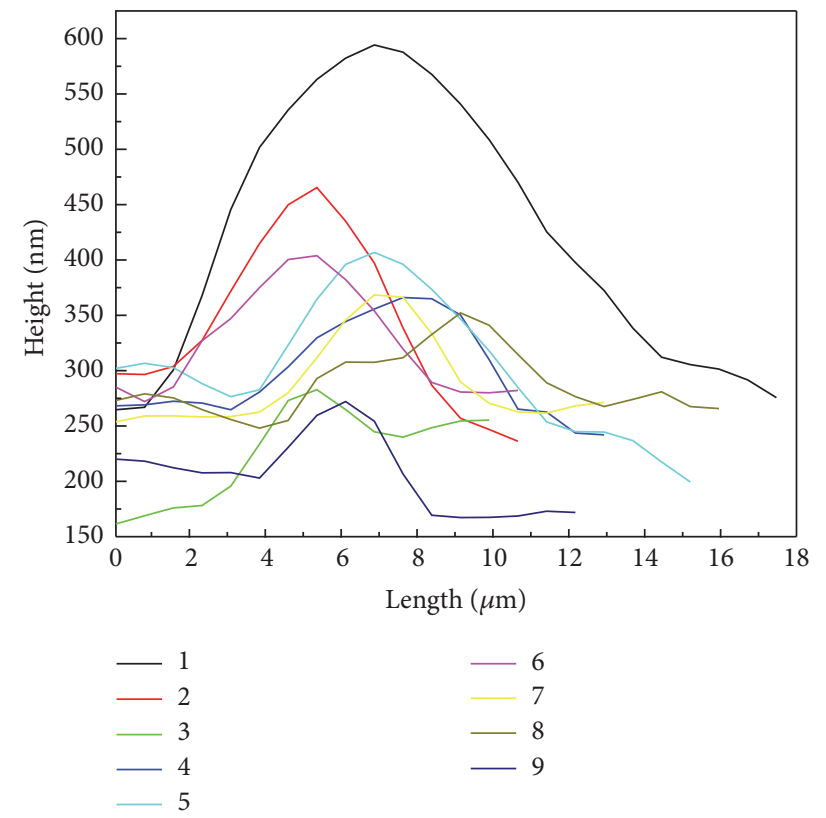

(f)

FIGURE 5: AFM analysis of the samples obtained at irradiation times of (a, c, and e) $2.5 \mathrm{~min}$ and (b, d, and f) $10 \mathrm{~min}$. (a) and (b) AFM 3D 20 $\times 20 \mu \mathrm{m}^{2}$ images; (c) and (d) AFM 2D $20 \times 20 \mu \mathrm{m}^{2}$ images with profiles; (e) and (f) linear profiles of the lines indicated at (c) and (d).

composed of $\mathrm{sp}^{2}$ bonds was detected by XRD. Moreover, the different emission wavelength luminescence bands arise from the different carbon structures such as the crystalline matrix and the polyaromatic clusters; that is, long wavelength emission would arise from graphite film bulk while the short wavelength bands come from the observed nanodots with a more oxidized surface [13]. This also explains why the emission increases with the film thickness and why the blue emission became important and all the emissions shift blue as nanodots became separated contributions with no interferences of the GaAs substrate; therefore the emission of the partially oxidized carbon nanodots is predominantly 

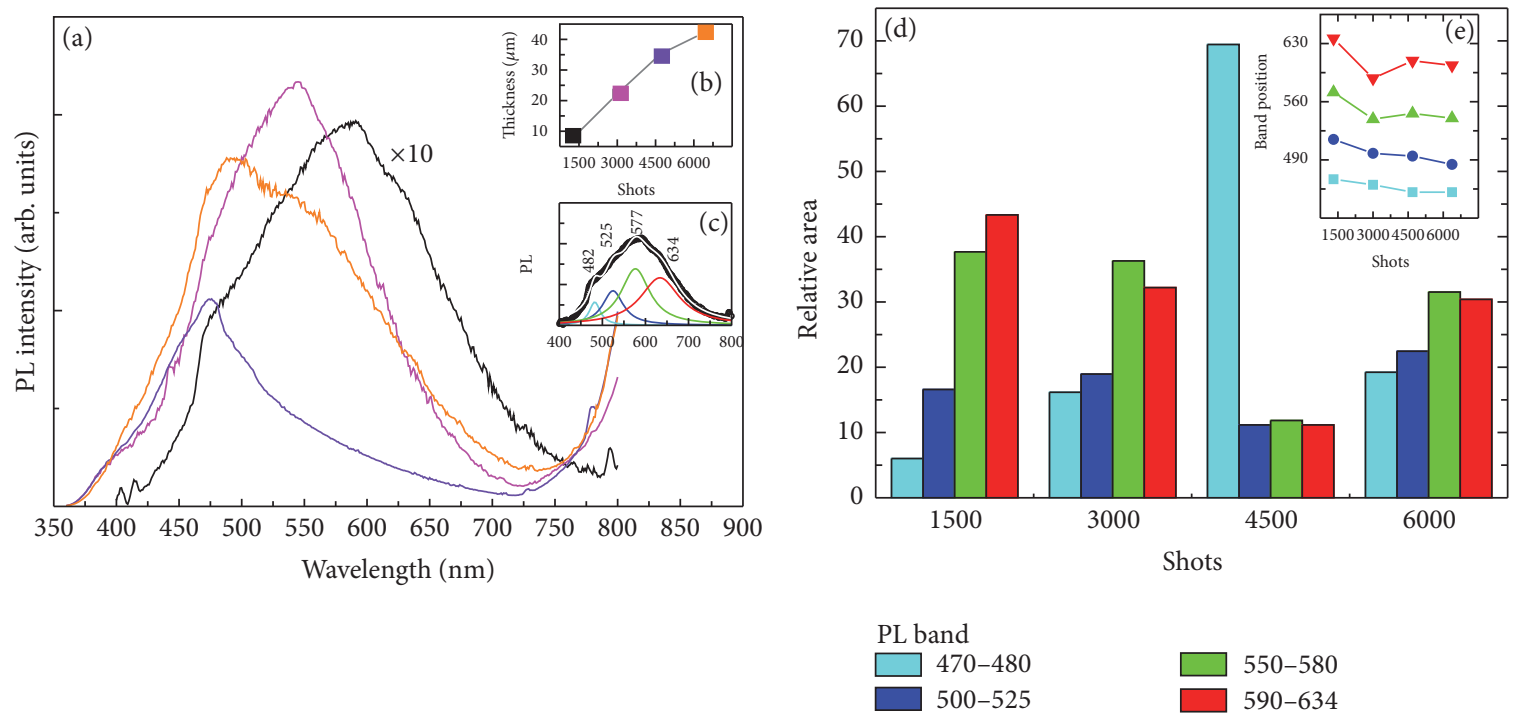

Figure 6: (a) Photoluminescence response of the deposited films, (b) film thickness evolution, (c) deconvolution of the PL spectra of the film prepared with 1500 shots, (d) relative area of the PL bands, and (e) PL band position.

observed $[1,13]$. The control of emission wavelength within the nanodot size control onto carbon films is subject of a future work.

\section{Conclusions}

Crystalline carbon films with splashed particles and carbon nanodots with sizes ranging from tens to hundreds of nanometers observed by AFM were prepared by low vacuum pulsed laser deposition onto GaAs substrates. Hexagonal and orthorhombic carbon was detected by XRD as well as structures that could be associated with carbon polyaromatic clusters. Photoluminescence bands at 475-480 nm, 540$550 \mathrm{~nm}, 590 \mathrm{~nm}$, and $625 \mathrm{~nm}$ were observed. It was found that the PL spectra increase intensity and display a blue shift as the film thickness increases. The proposed explanation is that GaAs influences the red emission. This influence is reduced as the carbon film is thicker, thus allowing observation of the blue luminescence of the carbon dots. The main contribution of the present work is the possibility of preparing $\mathrm{C}$ quantum dot-based solid-state devices by using a variation of pulsed laser deposition that does not require high/ultrahigh vacuum and that could arise as a reliable tool to prepare other kind of ordered structures.

\section{Competing Interests}

The authors declare that they have no competing interests.

\section{Acknowledgments}

The authors thank J. F. Martinez-Rocha, M.S., for experimental support. F. Caballero-Briones acknowledges SIP-IPN 2016-1804/0291 project and SIBE, EDI, and SNI grants for financial support.

\section{References}

[1] L.-C. Zhang, Q.-S. Li, Y.-F. Dong, and Z.-X. Ma, "Visible photoluminescence from $\mathrm{ZnO} /$ diamond-like carbon thin films," Optoelectronics Letters, vol. 8, no. 2, pp. 113-116, 2012.

[2] T. V. Cuong, V. H. Pham, Q. T. Tran et al., "Photoluminescence and Raman studies of graphene thin films prepared by reduction of graphene oxide," Materials Letters, vol. 64, no. 3, pp. 399401, 2010.

[3] Y. Wang and A. Hu, "Carbon quantum dots: synthesis, properties and applications," Journal of Materials Chemistry C, vol. 2, no. 34, pp. 6921-6939, 2014.

[4] V. Štengl, S. Bakardjieva, J. Henych, K. Lang, and M. Kormunda, "Blue and green luminescence of reduced graphene oxide quantum dots," Carbon, vol. 63, pp. 537-546, 2013.

[5] P. T. Murray and D. T. Peeler, "Pulsed laser deposition of carbon films: dependence of film properties on laser wavelength," Journal of Electronic Materials, vol. 23, no. 9, pp. 855-859, 1994.

[6] S. Palanco, S. Marino, M. Gabás, S. Bijani, L. Ayala, and J. R. Ramos-Barrado, "Micro-and nanoparticle generation during nanosecond laser ablation: correlation between mass and optical emissions," Optics Express, vol. 22, no. 4, pp. 3991-3999, 2014.

[7] M. Martino, A. P. Caricato, M. Fernández et al., "Pulsed laser deposition of active waveguides," Thin Solid Films, vol. 433, no. 1-2, pp. 39-44, 2003.

[8] K. Sturm, S. Fähler, and H.-U. Krebs, "Pulsed laser deposition of metals in low pressure inert gas," Applied Surface Science, vol. 154, pp. 462-466, 2000.

[9] M. Fernández-Guasti, E. Haro-Poniatowski, R. Diamant, L. Ponce, and E. Jiménez, "Pulsed-laser deposition of selenium," Journal of Materials Science, vol. 30, no. 24, pp. 6253-6256, 1995.

[10] T. Garcí, J. L. Sánchez, S. Díaz et al., "Deposition of polycrystalline $\mathrm{BaFe}_{12} \mathrm{O}_{19}$ thin films by using a Nd-YAG laser system," Materials Letters, vol. 28, no. 1-3, pp. 65-69, 1996.

[11] T. García, E. de Posada, L. Ponce et al., "Textured strontium ferrite thin films grown by PLD," Materials Letters, vol. 49, no. 5, pp. 294-298, 2001. 
[12] X. Yu and L. Qiang, "Preparation for graphite materials and study on electrochemical degradation of phenol by graphite cathodes," Advances in Materials Physics and Chemistry, vol. 2, no. 2, pp. 63-68, 2012.

[13] F. Gaspari, R. V. Kruzelecky, P. K. Lim, L. S. Sidhu, and S. Zukotynski, "Luminescence in hydrogenated amorphous carbon films grown by dc saddle-field glow-discharge decomposition of methane," Journal of Applied Physics, vol. 79, no. 5, pp. 26842688, 1996. 

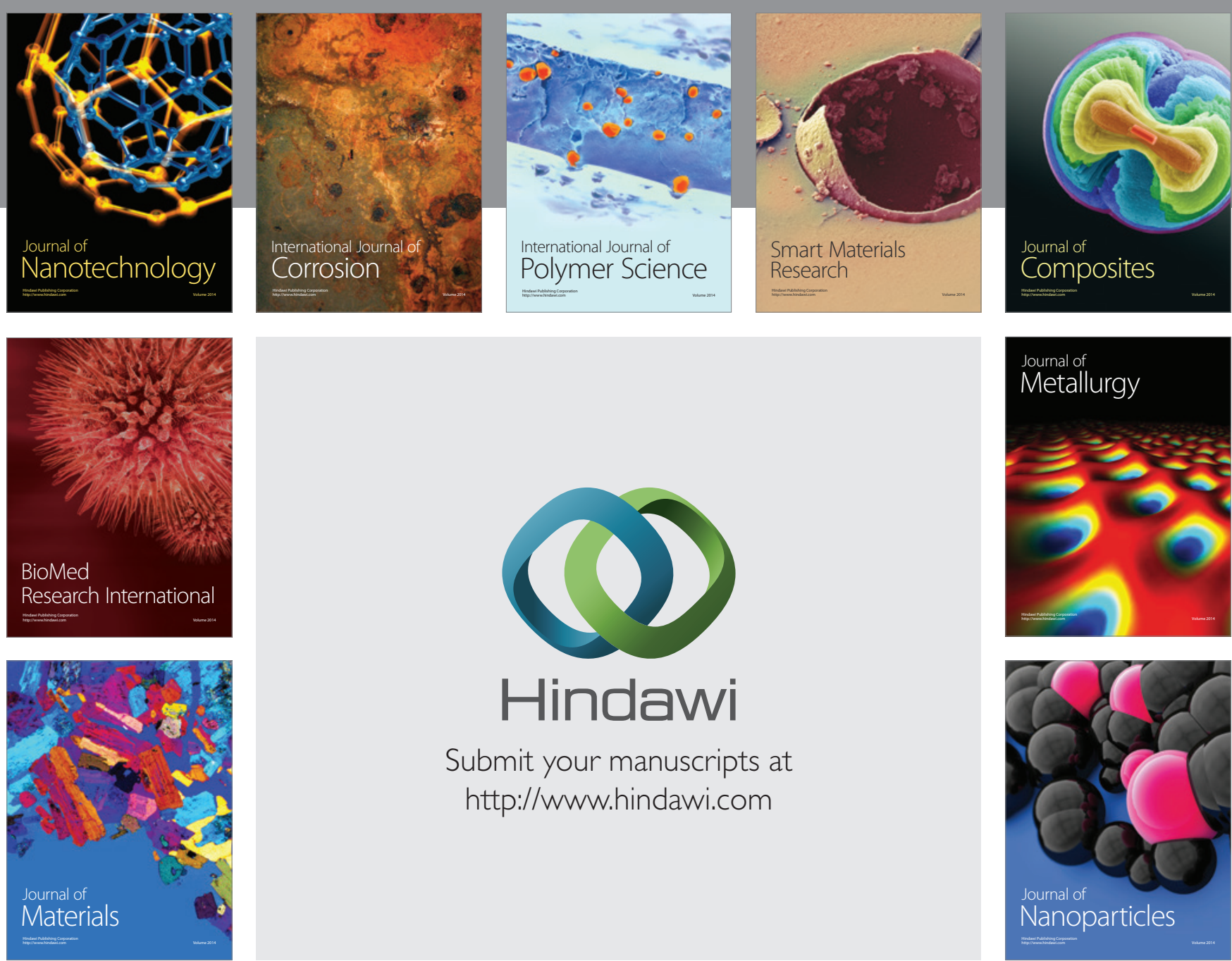

\section{Hindawi}

Submit your manuscripts at

http://www.hindawi.com

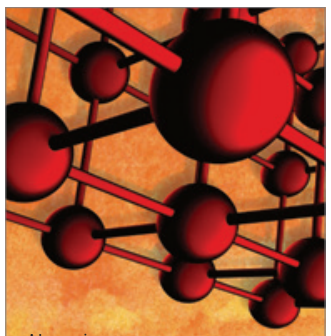

Materials Science and Engineering
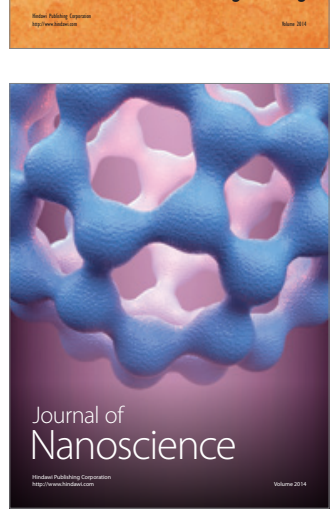
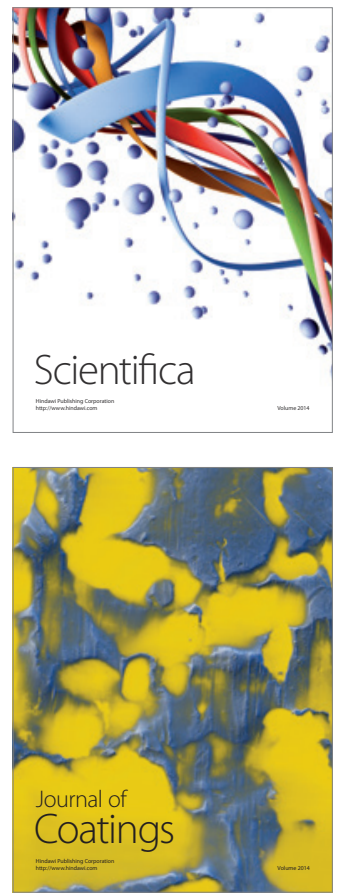
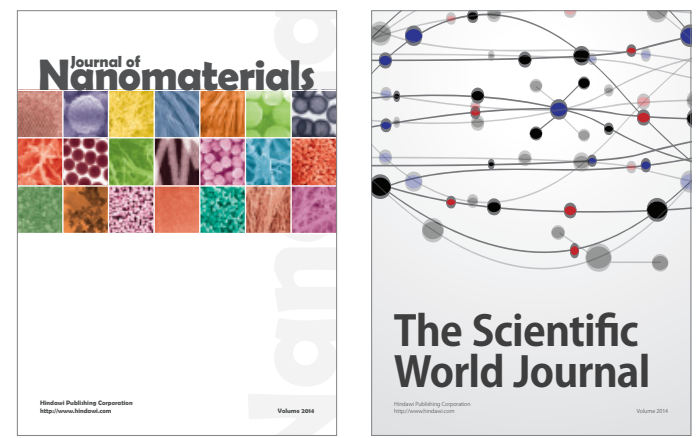

The Scientific World Journal
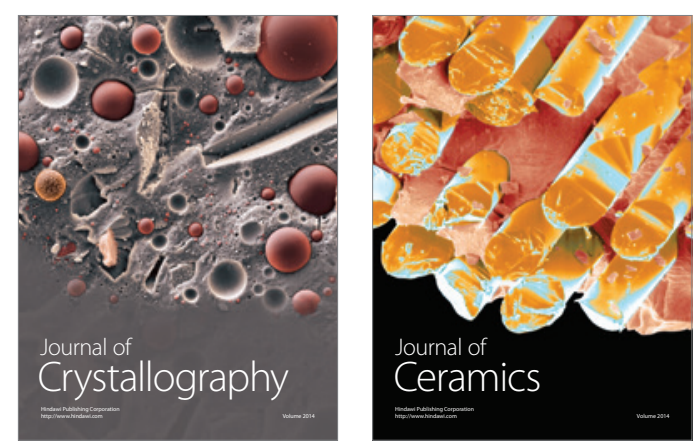
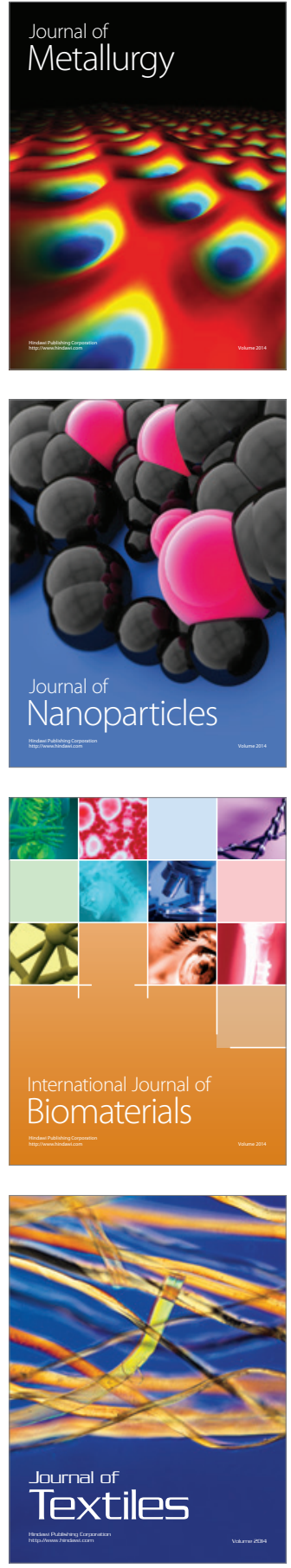